\title{
EL INVENTARIO DE PINTURAS DEL COLEGIO DE LOS IRLANDESES DE LA COMPAÑÍA DE JESÚS EN SEVILLA
}

\section{THE INVENTORY OF PAINTINGS OF THE COLLEGE OF THE IRISH OF THE SOCIETY OF JESUS IN SEVILLE}

\author{
Antonio Martín Pradas \\ Instituto Andaluz del Patrimonio Histórico. Consejería de Cultura y \\ Patrimonio Histórico. Junta de Andalucía. España \\ ORCID: 0000-0002-3464-5531 \\ antonio.martin.prada@juntadeandalucia.es
}

\begin{abstract}
Con el presente artículo pretendemos dar a conocer el inventario de pinturas del colegio de la Concepción de Nuestra Señora y de la Santa Fe Católica, también conocido como de San Patricio o de los irlandeses y de forma popular como de los Chiquitos de la Compañía de Jesús en Sevilla. El inventario fue realizado por Juan de Espinal, en 1767, con motivo de la expulsión de la orden de todos los reinos de Carlos III. En él se mencionan las pinturas del colegio e iglesia, donde se aporta el nombre de una serie de pintores sevillanos de los siglos XVII y XVIII, como Domingo Martínez, Gregorio de Espinal, Cristóbal de León, Miguel de Ayala, Juan de Roelas, Andrés Pérez, etc.

Palabras clave: Compañía de Jesús; Colegio de San Patricio; Colegio de la Concepción de Nuestra Señora y de la Santa Fe Católica; Colegio de los Irlandeses; inventario de pinturas.
\end{abstract}

With this article we aim to show inventory of painting from Concepción de Nuestra Señora y Santa Fe Católica, also known as Saint Patrick or the Irish and popular way as "Los Chiquitos de la Compañía de Jesús de Sevilla". The inventory was carried out bay Juan de Espinal, in 1767, on the occasion os the expulsion of the order from all the kingdoms of Carlos III. In it the paintings of the school and church are mentioned, where the name of a series of Sevillian painters of the 17th and 18th centuries, such as Domingo Martínez, Gregorio de Espinal, Cristóbal de León, Miguel de Ayala, Juan de Roelas, Andrés Pérez, etc.

Keywords: Company of Jesus; School of San Patricio; School of the Conception of Our Lady and of Santa Fe; School of the Irish; paint inventory. 


\section{EL COLEGIO DE SAN PATRICIO, ORIGEN Y FUNDACIÓN (1612-1767)}

La Misión de Irlanda comenzó a funcionar con Carlos V y Felipe II, aunque fue implantada oficialmente por Felipe III. Esto dará pie a la creación de una red de colegios irlandeses distribuidos por Europa. En nuestro país se crearon siete colegios: Salamanca en 1592, Valladolid en 1589, Santiago de Compostela en 1605, Sevilla en 1609, Valencia en 1628, Madrid en 1629 y Alcalá de Henares en $1649^{1}$, algunos de ellos regidos por la Compañía de Jesús.

Esta Misión fue la reacción de la monarquía española para mantener vivo el catolicismo en Irlanda, siendo la respuesta más eficaz que las contiendas militares, para frenar a Inglaterra ${ }^{2}$. Para ello se crearon una serie de colegios en España en los que se daba formación especial a los colegiales irlandeses, a los que se hacía un examen previo para poder validar la condición de misión "apto" para ser trasladado a la isla a predicar el catolicismo y desarrollar su labor pastoral. A finales del siglo XVI se fueron entregando, por parte de la corona, ayudas económicas que gestionaba Consejo de Hacienda y aprobaba el rey, a aquellos colegiales o presbíteros que lo solicitasen. Esta ayuda se institucionalizó con el nombre de Viático, que constaba de 100 ducados anuales para ayudas de ropa, mantenimiento, libros y viaje de vuelta en su caso a Irlanda ${ }^{3}$.

Los orígenes del colegio irlandés de Sevilla se remontan, a "una Junta o Seminario de estudiantes irlandeses de Sevilla", financiada por las limosnas que autorizó, en junio de 1612, el nuncio de España Antonio Caetani. Al parecer, la primera corporación estaba situada cerca de la parroquia del Sagrario, hacia el llamado Horno de las Brujas ${ }^{4}$. Esta sería la base que, el padre Tomás ${ }^{5}$ Stapleton $^{6}$, tomó en 1612 para iniciar el colegio. Este padre fue un venerable sacerdote asesinado en Dublín, formado en el colegio de Lisboa, quien se trasladó a Sevilla con un grupo de compañeros para refundar el colegio de los irlandeses, ya que los miembros de este seminario habían fallecido, como consecuencia de la epidemia

${ }^{1}$ García Hernán, Enrique: "Estudios sobre la Misión de Irlanda". CSIC, Madrid. http://www.irishinspain.es/irlandeses/doc/research/estudiosmisionirlanda.php (10-7-2020). La Misión de Irlanda: Nombre oficial con el que era conocida la gestión de los viáticos (es decir, las ayudas a estudiantes y clérigos irlandeses para regresar a Irlanda).

${ }^{2}$ La Misión de Irlanda. http://www.irishinspain.es/irlandeses/doc/research/mi.php (177-2020).

${ }^{3}$ García Hernán, Enrique: "Estudios sobre la Misión de Irlanda". CSIC, Madrid. http://www.irishinspain.es/irlandeses/doc/research/estudiosmisionirlanda.php (10-7-2020). La Misión de Irlanda: Nombre oficial con el que era conocida la gestión de los viáticos (es decir, las ayudas a estudiantes y clérigos irlandeses para regresar a Irlanda).

${ }^{4}$ Bravo Lozano, 2016.

${ }^{5}$ En la documentación consultada se le denomina indistintamente Tomás, Theobald o Theobaldo así como su apellido Stapleton o Estapleton.

${ }^{6}$ Murphy, 2003: 565. 
de peste. Contó con la intervención del duque de Bragança quien mediaría para conseguir el apoyo del arzobispo de Sevilla, el patrocinio del canónigo don Félix de Guzmán 7 , el asistente de la ciudad y particulares devotos les apoyaron llevar a buen puerto su proyecto.

El seminario se puso en marcha sin rentas fijas, dependiendo de las limosnas de particulares. Como podemos observar los principios del colegio de Sevilla, se debieron al esfuerzo de varios benefactores, que se dedicaron desde un principio a recoger a "jóvenes irlandeses / que venían huyendo de su patria, con el ánimo de instruirse fun / damentalmente en las verdades católicas y de poder después regre I sarse a ella a consolar a sus hermanos y afirmarlos en la religi I ón con su doctrina y ejemplo, ejerciendo entre los mismos el mi / nisterio de Párroco”. En este punto es importante tener presente a Jerónimo de Medina Ferragut, que puso a disposición de estos jóvenes su casa, en la calle de la Garbancera ${ }^{8}$. Desde un principio compartió su vivienda con ellos "movido de / ver la grande virtud y cristiandad con que vivían, lo bien que empleaban / el tiempo y la suma estrechez y pobreza en que se I hallaban por subsistir únicamente de limosnas". Este sentimiento le llevó a que les donara sus casas, así como un corral de vecinos contiguo, mediante escritura firmada el 11 de abril de 1616 ante el escribano público Pedro del Carpio. En la escritura se hace donación al licenciado Amaro Regano, que era el rector, y a los colegiales, con la condición de que las referidas casas debían convertirse en colegio bajo la advocación de Nuestra Señora de la Concepción y de la Santa Fe Católica.

Debido a la estrechez de las casas y a que con posterioridad pasó la dirección del colegio a manos de la Compañía de Jesús, el donante aceptó que se pudiesen vender las casas y que el colegio fuese trasladado a otro lugar. Para ello otorgó escritura el 31 de julio de 1624 ante el escribano público de Guillena, Agustín de Talavera ${ }^{9}$. Aun así, el colegio permaneció en el mismo lugar, remediando la estrechez con la compra de varias casas aledañas que fueron agregándose en varias épocas $(1656,1717,1720,1721$ y 1734), formando un conjunto edilicio interesante.

El principal defensor de la fundación de este colegio fue don Félix de Guzmán, arcediano y canónigo de Sevilla y obispo electo de Mallorca, tío del futuro conde-duque de Olivares. Este señor vivía frente a la casa que, Jerónimo de Medina Ferragut, había convertido en albergue para jóvenes irlandeses, como gran admirador de esta labor les ayudaba continuamente con limosnas a lo largo del año. Cada vez se fue interesando más, hasta el punto que lo comunicó al rey

${ }^{7}$ Gracía Hernán, 2006: 10-11.

${ }^{8}$ Actual calle Jesús del Gran Poder.

9 Biblioteca Capitular Colombina Sevilla, (BCCS). Papeles del Conde del Águila. Sig. 59-6-11. Capitulo de Carta escrita al Sr. Campomanes en 14 de octubre de 1767, sobre la fundación del Colegio de los Irlandeses de Sevilla, s/f. 
Felipe III, quien contestó el 21 de octubre de 1616, ordenando al Arzobispo de Sevilla que encomendara esta labor a don Félix de Guzmán "dejando a / su disposición la forma y modo de sustento y los demás preciso por su / continuación y buen acomodo de los colegiales".

Tras ponerse al frente el arcediano, decidió dejar su caudal a un Patronato que fundó, según consta en escritura del 5 de junio de 1625, firmada ante el escribano público de Sevilla, Juan Bautista de Contreras.

De forma paralela fue informado el papa Pablo $\mathrm{V}$, quien expidió dos breves a favor del colegio. El primero de ellos con fecha 10 de julio de 1617, donde concedía la gracia de que los alumnos pudiesen ser ordenados extra tempora "sin la precisión de intersticios y sin tener necesidad de / título de patrimonio ni de beneficio eclesiástico, y si solo el de / las misiones a Irlanda”, todo ello bajo testimonios escritos que les debía de dar su presidente, Mauro Rejano. El segundo breve, fechado el 1 de agosto del mismo año, concedía al ordinario la licencia para decir misas y recibir al Sacramento de la Eucaristía, los colegiales y las personas que iban a la capilla que se había habilitado.

Debido al buen funcionamiento, vocación de los alumnos, virtud, literatura y celo, se propuso que el establecimiento fuese cedido a la Compañía de Jesús para que creara el colegio Irlandés de Sevilla. Esto fue avalado por Felipe III con dos cartas dirigidas al entonces provincial padre Agustín de Quirós, la primera fechada en Belén (Portugal) el 22 de junio de 1619 y la segunda en Lisboa 25 de julio del mismo año. Esta petición fue aceptada por el General de la Compañía, que en estos momentos era el padre Mucio Vitelleschi, tomando posesión del colegio la Compañía de Jesús el 20 de agosto de $1619^{10}$.

El primer rector jesuita fue el irlandés Richard Conway (Ricardo Conveo), quien al parecer completó el nombre del colegio en la relación fundacional de $1620^{11}$. A partir de este momento todos los rectores fueron de nacionalidad irlandesa, llegando a darse un pleito, en 1647, entre el Provincial de Andalucía y los colegiales irlandeses que se negaban a admitir que les rigiese un rector español ${ }^{12}$.

En los comienzos de la fundación, el colegio, se vio favorecido con cierta prosperidad avalada por una serie de donaciones, pero con la llegada del siglo XVIII se inició el declive siendo considerado un colegio pobre y de recursos limitados.

${ }^{10}$ Biblioteca Capitular Colombina Sevilla. Papeles del Conde del Águila. Sig. 59-611. Capítulo de Carta escrita al Sr. Campomanes en 14 de octubre de 1767, sobre la fundación del Colegio de los Irlandeses de Sevilla, s/f.

11 Bravo Lozano, 2016.

12 Archivo Histórico Nacional (AHN). Consejos, 25641, Exp. 21, año 1647. El Provincial de Andalucía contra los colegiales del colegio de los Irlandeses, de Sevilla, sobre no admitir rector español. 
En este lugar permanecieron los colegiales hasta que la noche del 2 al 3 de marzo de 1767, se llevó a efecto la expulsión de la compañía de Jesús, a través de la pragmática sanción emitida por Carlos III y su gobierno.

\section{FINALIDAD Y FUNCIÓN SOCIAL DEL COLEGIO}

El colegio de la Concepción de Nuestra Señora y de la Santa Fe Católica, popularmente conocido como colegio de irlandés o de los irlandeses, fue una institución creada con la finalidad de "educar a estudiantes irlandeses, prefectos Gramáticos, de conocida habilidad, juicio y virtud, y de limpia y pura sangre de Padres y ascendentes católicos, y honrados; de cuyas prendas y partidas hace examen e información exacta y rigurosa, allá en Irlanda, el Padre superior de las misiones de la Compañía de Jesús, sin cuyo informe y recomendación y patente no pueden ser admitidos en este seminario" 13 .

Una vez recibidos en el colegio los alumnos se dedicaban a estudiar Filosofía, Teología, Escolástica y Moral, así como al ejercicio de controversias de la Fe católica. Los integrantes del colegio desarrollaban sus estudios en el propio colegio aunque se trasladaban al cercano de San Hermenegildo para completar sus estudios de tres años en Artes y cuatro de Teología ${ }^{14}$. Acto seguido aplicaban estos conocimientos mediante ejercicios literarios y de gramática, lecciones, conferencias escolásticas, casos de moral, controversias y sabatinas. Un programa educativo que seguía los parámetros de la Ratio Studiorum, desarrollando diversas labores en otros centros religiosos de la ciudad ${ }^{15}$.

La finalidad última es que volviesen a su patria para predicar el Evangelio, administrar los santos sacramentos, consolar y alentar a sus paisanos y combatir a los herejes. El gobierno de Inglaterra imponía graves sanciones y penas a estos estudiantes que se trasladan a España, por lo que a su vuelta eran perseguidos y apresados, llegando incluso a ser condenados a la horca, siendo remunerados sus denunciantes ${ }^{16}$. Los estudiantes, llevaban a cabo un juramento público antes de tomar la Beca de colegiales en presencia del padre rector. El juramento consistía en que volverían a Irlanda a predicar el Santo Evangelio. El

13 Archivo Municipal de Sevilla (AMS). Papeles del Conde del Águila, sección 11, tomo 65 en folio, documento 36, p. 340 r. "Noticias que ofrece a los ojos de la Piedad Cristiana el Colegio Irlandés de la Compañía de Jesús de Sevilla, en que da a conocer lo singular y apreciable de su instituto, y la grande pobreza a que ha venido en este tiempo".

${ }^{14}$ Ortiz de Zúñiga, 1796: 281.

15 Bravo Lozano, 2016.

${ }^{16}$ AMS. Papeles del Conde del Águila, sección 11, tomo 65 en folio, documento 36, p. 340v. "Noticias que ofrece a los ojos de la Piedad Cristiana el Colegio Irlandés de la Compañia de Jesús de Sevilla, en que da a conocer lo singular y apreciable de su instituto, y la grande pobreza a que ha venido en este tiempo". 
acto se desarrollaba en la iglesia del colegio, tras oír la misa presidida por el rector. En este momento el colegial recibía la Beca, pero solo se le colocaba sobre un hombro, a continuación se procedía a leer en voz alta su juramento ante el Santísimo Sacramento. Este juramento, lo llevaba escrito en un papel firmado y se lo entregaba al padre rector. En ese momento recibía la comunión, a continuación se le colocaba la Beca cubriendo ambos hombros. De forma paralela, llevaban a cabo otra serie de juramentos entre los que se encontraba la observancia de sus leyes y constituciones.

Este colegio, al igual que el de San Gregorio o de los Ingleses, participó en las fiestas que se realizaron, durante ocho días, en honor a la canonización de San Luis Gonzaga y San Estanislao de Kostka como podemos observar, en la publicación de la oración panegírica que predicó el padre Domingo García ${ }^{17}$.

El número de colegiales osciló, a lo largo de su historia, con distinto número de seminaristas, siempre en función de sus ingresos. Sabemos que en el siglo XVIII sus fondos eran lo suficientemente escasos como para mantener a cinco, sus sirvientes, así como una capilla o iglesia con sacristía para su uso ${ }^{18}$.

Los seminaristas irlandeses eran reconocidos en la ciudad de Sevilla por su vestimenta: manto azul oscuro y beca parda, donde llevaba bordado el JHS.

\section{EL COMPLEJO EDILICIO}

El colegio contaba con una iglesia de medianas proporciones, de tres naves cortas, divididas por arcos sobre columnas de mármol, pisando sobre las dos colaterales las tribunas y algunas habitaciones ${ }^{19}$, similar a la actual iglesia de San Gregorio, perteneciente al colegio inglés. En su interior se distribuían una serie de retablos, el mayor estaba dedicado a la Inmaculada con una escultura de Juan Martínez Montañés. En las cabeceras de las naves laterales se situaban uno con la advocación de San Patricio, escultura realizada por Marcelino Roldán Serrallonga y policromada por Domingo Martínez en 1739, y otro en la nave opuesta donde se veneraba el Cristo de la Buena Muerte. Existían otros retablos distribuidos por las naves laterales como el de San Juan Francisco Regis, etc. Al templo se accedía desde la Calle Garbancera, hoy día Jesús del Gran Poder, cuya portada estaba situada justo frente a la calle Pescadores. (Figura 1).

Uno de los retablos laterales estaba dedicado a San Patricio, patrón de los irlandeses, en él se disponían siete cuadros de la vida del santo, siendo de mayor tamaño el que remataba el altar. Estos cuadros fueron pintados por Domingo Martínez. Además, se distribuían por la iglesia 25 cuadros, diez de ellos formaban

\footnotetext{
17 García (S.I.), 1727.

18 Carrera, 1817: 38-39.

19 Madoz, 1849: 331. González de León, 1839: 231. González de León, 1844: 206.
} 
parte de un retablo donde se representaba la vida de Cristo, ejecutadas por el suegro de Juan de Espinal.

Anexa al templo se encontraba la sacristía, donde además del mobiliario propio de este recinto se distribuían por sus paredes 10 cuadros, uno de ellos realizado sobre cobre. Junto a ésta, se disponía la sala de conferencias baja, presidida por un gran cuadro de San Patricio, con representaciones de su vida alrededor y en la parte baja algunos colegiales.

El colegio contaba con un patio de medianas proporciones, en cuyo corredor bajo se distribuían 10 lienzos. El patio estaba formado por pilares rectangulares sobre los que cabalgaban arcos de medio punto. Éste se comunicaba con la portería a través de un corredor o pasillo donde se situaba otro lienzo de gran formato.

En la portería se disponía un cuadro que representaba el martirio de Theobaldo Stapleton, que fue el primer rector de este colegio y otro lienzo.

Anexo al patio se situaba el refectorio, acorde a las necesidades de los colegiales, donde se disponían dos cuadros, uno de ellos de gran formato. Además tenía una serie de aposentos, entre los que destacaba el aposento rectoral bajo, con un lienzo de dos varas. La escalera principal, en un lateral del patio, ponía en comunicación la planta baja y la alta, presidida por un lienzo de gran formato de la Virgen del Rosario.

En la planta alta se daban una serie de dependencias: aposento rectoral, posiblemente para vivir en verano en la plata baja y en invierno en la alta y una sala de conferencias, así como el aposento del Presidente, la librería, corredores y dormitorios de los colegiales. Además, el colegio, contaba con cocinas, letrinas, pozo y corral que daba a la Alameda. El conjunto se formó de la suma de casas que se fueron comprando a lo largo de los siglos XVII y XVIII, hasta formar un conjunto de edificaciones útiles pero no homogéneas.

\section{DESTINO DEL COLEGIO TRAS LA EXPULSIÓN DE LA COMPAÑÍA DE JESÚS}

Esta expulsión, llevada a cabo en la madrugada del 3 de marzo del mismo año, fue significativa porque constituyó el desmantelamiento del sistema educativo que había formado a generaciones de jóvenes durante sus casi dos siglos de existencia; también porque significó la desmembración y el reparto del patrimonio mueble e inmueble de la Compañía ${ }^{20}$.

Tras la expulsión de los jesuitas se abrieron expedientes para la venta de sus bienes, atendiendo a las solicitudes de otras iglesias y parroquias de la ciudad y localidades vecinas en las que pedían se les donasen ornamentos y objetos de plata para el culto. En este momento se dieron por extinguidas las congregaciones y

${ }^{20}$ Martín Pradas/Carrasco Gómez, 2005: 246. 
cofradías fundadas en los colegios, aunque debían de cumplir con sus rentas las cargas anexas y las pensiones asignadas a los regulares expulsados. Este colegio, al igual que otros colegios de irlandeses e ingleses regidos por la Compañía de Jesús, fueron excepciones que justificaron la regla, ya que sus rentas y enseres fueron adscritos a otro colegio.

$\mathrm{Al}$ expulsar Carlos III a los jesuitas de todos sus reinos, el gobierno se dio cuenta que los colegios irlandeses e ingleses formaban parte de la misión que la corona había emprendido en contra de Inglaterra en la defensa del catolicismo. Por ello decidió agrupar los colegios en uno. Por ejemplo, el colegio de San Gregorio o de los ingleses se unió al colegio de San Albano de Valladolid, mientras que el de los irlandeses lo hizo en el de San Patricio de Salamanca.

En la consulta realizada por el Consejo el 31 de mayo de 1768, se decidió por Resolución Real ${ }^{21}$ dar al colegio una doble finalidad, llegando incluso a nombrarlo de forma distinta, aunque con dos nombres conocidos por la ciudad:

El Colegio de los Irlandeses ${ }^{22}$

8. Este queda vacante por la reunión, que ha resuelto $S$. M., de todos estos colegios en el de Salamanca, y se destina para Seminario de Nobles.

El Colegio de los Chiquitos

9. Se aplica para sustituir en él los Estudios de Gramática, que existían en el de San Hermenegildo, de donde debe separarse para mayor capacidad del Hospicio.

Hay que tener en cuenta que el Colegio de San Hermenegildo fue destinado a Hospicio General, con separación de hombres, mujeres y niños.

Como podemos comprobar, las rentas y enseres del colegio de los irlandeses fueron unificados en el Colegio de San Patricio de Salamanca. El edificio salmantino sufrió graves daños durante la invasión francesa, por lo que cuando volvieron los colegiales se encontraron que era imposible reconstruirlo. Ante esta situación el colegio de San Patricio fue reubicado en el Colegio del Arzobispo Fonseca o Colegio mayor de Fonseca, donde permaneció hasta 1952, año en el que el gobierno de la dictadura decidió suprimirlo para ser trasladados a Saint Patrick College de Maynoot ${ }^{23}$.

El edificio, casa e iglesia fueron vendidas por las temporalidades municipales a un vecino de la ciudad, cuyos herederos la volvieron a vender en 1803. La compra fue realizada por una congregación que pretendía crear "un recogimiento $o$ seminario de niñas huérfanas, bajo la dirección de las beatas de San Antonio de Padua", cuya fundación se había realizado en unas casas linderas al colegio. Tras tomar posesión llevaron a cabo una serie de obras en la casa e iglesia, anexionando

${ }^{21}$ COLECCIÓN General de las Providencias, 1769: 96-97.

${ }^{22}$ Creemos que es un error habitual, confundir irlandeses con ingleses. En este caso sería de los ingleses.

${ }^{23}$ Gómez Rivas, 2009: 275. 
otras casas aledañas de la calle del Potro, trasladándose al recinto el 5 de octubre de $1805^{24}$.

Pascual Madoz, recoge que el San Patricio del retablo mayor fue sustituido por una escultura de San Antonio de Padua. El Beaterio estuvo en funcionamiento, según González de León hasta 1837, "saliendo de él las beatas y quedando sin uso la iglesia, que es de tres naves muy pequeña, y sobre su puerta está aún la imagen de San Antonio en Barro" ${ }^{25}$. Con posterioridad el edificio fue vendido y su iglesia convertida en almacén de maderas, siendo el espacio del colegio reutilizado como casa de vecinos, según Francisco Collantes de Terán y Luis Gómez Estern, en su obra Arquitectura civil sevillana. Al describir las dos fotografías que aportan, una del exterior del edificio y otra del patio, se refiere a que en ella "existen restos del colegio jesuita con el nombre de "los ingleses", entre ellos el patio con arcos de medio punto sobre pilares en planta baja, y balcones separados por pilastras en la superior" ${ }^{26}$, sin duda confundió ingleses por irlandeses.

El estado de conservación del edificio era lamentable en la década de 1960, aunque parece ser que aún estaba en uso. En una serie de fotografías, que hemos localizado fechadas el 16 de abril de 1968, se ve el acopio de material de tejas y maderas, como si se estuviese desmantelando. En las fotografías observamos el patio principal del colegio, de planta cuadrada, formado por cuatro arcos de medio punto sobre pilares en la planta baja y en la superior por cuatro balcones. Uno de los frentes se encuentra tapiado con ventanas dobles, en la galería inferior, y simples en la superior, posiblemente porque diese a la iglesia o sacristía. Respecto a la decoración recuerda a las obras realizadas por el hermano Pedro Sánchez en otros colegios de la Bética, con decoración de ménsulas en la clave de los arcos y molduras enmarcando los vanos superiores e inferiores. (Figuras 2, 3, 4, 5, 6 у 7).

La destrucción total del edificio llegó en 1975 cuando se decidió construir el Multicines Alameda, con el proyecto de los arquitectos E. Escribano de la Cuadra y Antonio Delgado Roig ${ }^{27}$. El nuevo edificio que incluía cines y una zona de bares y comercios, fue inaugurado el 1 de marzo de $1977^{28}$.

${ }^{24}$ Carrera, 1817: 71.

${ }^{25}$ Gutiérrez Núñez/Hernández González, 2011: 289-305.

${ }^{26}$ Collantes de Terán Delorme/Gómez Estern, 1999: 220-221.

27 Archivo Fundación FIDAS. Proyecto visado en marzo de 1975 y que se localiza en Alameda de Hércules 4-5 y calle Jesús del Gran Poder 64-66.

${ }^{28}$ Hemeroteca ABC de Sevilla. Martes 1 de marzo de 1977, p. 39, col. 3. Presentación a la prensa de Multicines Alameda. 


\section{INSTRUMENTOS PARA LA EXPULSIÓN: "INVENTARIOS DE PINTURAS”}

Los instrumentos legales diseñados para expulsar a los jesuitas se centran fundamentalmente en una serie de documentos que fueron publicados en Madrid por la Imprenta Real de la Gazeta en 1767, bajo el título "Colección General de las Providencias hasta aquí tomadas por el Gobierno sobre el estrañamiento y ocupación de temporalidades de los Regulares de la Compañia, que existían en los Dominios de Su Majestad de España, Indias, e Islas Filipinas a conseqüencia del Real Decreto de 27 de febrero, y Pragmática-Sanción de 2 de abril de este año".

Los instrumentos legales ideados para ejecutar la expulsión, no dejaron ni un cabo suelto, abarcando tanto el ámbito socioeconómico como el político. Desde el punto de vista social, se desterró a todos los jesuitas a los Estados Pontificios y obligó al Papa Clemente XIII a disolver la Orden, aunque no llegó a hacerlo si lo hizo su sucesor. Con respecto al ámbito político se ocultaba en la Pragmática Sanción "con fuerza de Ley" ${ }^{29}$ su verdadero móvil.

Desde el punto de vista económico se aseguraron de poner a buen recaudo el dinero incautado en los distintos colegios ${ }^{30}$, sin olvidarse de encargar la realización de inventarios de capellanías, juros, censos ${ }^{31}$, misas cantadas y rezadas, de especies como granos y paja, de animales como bueyes, caballos, ovejas y cabras ${ }^{32}$ y por último, de los bienes muebles e inmuebles, sus arrendadores y personas que debían dinero a la Compañía ${ }^{33}$.

${ }^{29}$ PRAGMÁTICA SANCIÓN DE SU MAGESTAD, en fuerza de Ley, para el estrañamiento de estos Reynos a los Regulares de la Compañía, ocupación de sus Temporalidades, y prohibición de su restablecimiento en tiempo alguno, con las demás precauciones que expresa. El Pardo 2 de abril de 1767. En COLECCIÓN General de las Providencias, 1769: 36-45.

${ }^{30}$ REAL Cédula, sobre crear Depositaría General para el resguardo y manejo de los caudales de los jesuitas de España, é Indias, después de su estrañamiento. En COLECCIÓN General de las Providencias, 1769: 74-92.

${ }^{31}$ REAL Cédula, que prescribe el modo con que han de pagar los Pueblos los Censos, deudas y cánones que pagaban a los Jesuitas. En COLECCIÓN General de las Providencias, 1769: 93-98. CARTA Circular sobre los lugares de monte, censos o efectos que tenían las casas de los Jesuitas a su favor, fuera del Reyno, los Juros y efectos de villa y pinturas que se hallen en ella (Madrid, 16 de septiembre de 1767). En COLECCIÓN General de las Providencias, 1769: 130-131.

${ }^{32}$ CARTA Circular dirigida a los Comisionados de los cuatro reinos de Andalucía, Extremadura y La Mancha, para que suspendan la venta, y tengan a la disposición de D. Pablo de Olavide los ganados, granos, muebles y aperos de labor, de las Casas de los Jesuitas, en cuya ocupación de Temporalidades están entendiendo (Madrid, 10 de julio de 1767). En COLECCIÓN General de las Providencias, 1769: 127-128.

${ }_{33}$ CARTA circular, mandando que las Haciendas que fueron de los Jesuitas, elegidas por Escusado, paguen los Diezmos, por ahora, como acostumbraban pagarlos dichos regulares. Madrid 12 de junio de 1767. En COLECCIÓN General de las Providencias, 1769: 93. 
Estos inventarios se realizaron separando, intencionadamente, determinados objetos atendiendo a varios supuestos, según su uso, material, valor económico o valor artístico.

Respecto a los inventarios de pintura, parten de una Carta Circular fechada en Madrid el 16 de septiembre de 1767, en la que se recomienda, por consejo de Don Antonio Rafael Mengs, primer pintor del Rey "que las pinturas de buenos Autores, que pueda haber en los Colegios de la Compañía, y se pongan a la venta, no conviene que se saquen fuera del Reino, ha acordado igualmente el Consejo envíe usted lista de las pinturas de esa casa de su cargo, con expresión de lo que representan, y su calidad, para acordar lo conveniente" 34 . Antonio Rafael Mengs, nombró, el 25 de abril de 1769, a Antonio Ponz para que se trasladase a los colegios y casas para tasar y separar las pinturas, informando al Consejo.

El 8 de julio de 1769, Don Pedro Rodríguez Campomanes, promulgó una nueva circular relativa a "Pinturas y otras cosas de las nobles Artes", notificando la importancia que tenía saber todo lo que había en los colegios y casas relativos a "Artes del dibujo, como son Modelos, Estampas, medallas, Museos, Inscripciones, y demás monumentos, que puedan convenir a la instrucción de los Profesores y beneficio público" 35 .

Tras recibirse en Sevilla la Carta Circular fechada en Madrid el 16 de septiembre de 1767, en la que se solicitaba entre otras cosas "envie usted lista de las pinturas de esa casa de su cargo", se comenzó a realizar el inventario de los distintos establecimientos que tenía la Compañía de Jesús en Sevilla.

\section{EL INVENTARIO DE PINTURAS, SU AUTOR Y PINTORES ENUMERADOS}

El inventario fue realizado y firmado por Juan de Espinal, pintor de Sevilla y yerno de Domingo Martínez, el 26 de septiembre de 1767. Este instrumento estuvo avalado por la presencia de don Matías de Ulloa, Alcalde del Crimen de la Real Audiencia de la ciudad de Sevilla, quien acompañó a Espinal en todo momento durante la realización del mismo. El documento se titula Lista de pinturas, que se halla en el Colegio / de los Irlandeses de esta ciudad de Sevilla, su calidad I

${ }^{34}$ CARTA Circular, sobre los lugares de monte, censos, o efectos que tenían las Casas de los jesuitas a su favor, fuera del Reyno, los Juros, y efectos de Villa, y pinturas que se hallen en ellas. Madrid 16 de septiembre de 1767. En COLECCIÓN General de las Providencias, 1769: 130-131.

${ }_{35}$ NUEVA Circular a los Comisionados, sobre Pinturas y otras cosas de las nobles Artes. Parte tercera. Madrid 8 de julio de 1769. En COLECCIÓN General de las Providencias, 1769: 145-146. 
clases y autores, según el reconocimiento que / judicialmente ha hecho don Juan de Espinar, artista / pintor de esta dicha ciudad ${ }^{36}$. (Figura 8).

Juan de Espinal fue el encargado de realizar el inventario de pinturas del Colegio de San Gregorio o de los ingleses de Sevilla el 24 de octubre de 1767. Este colegio fue anexionado al de San Albano de Valladolid. Parte de sus pinturas fueron vendidas, otras se llevaron al Alcázar como modelo para los estudiantes de bellas artes, otras fueron a la Corte, otras se conservan en el colegio de Valladolid y otras fueron compradas por la Real Academia de Medicina de Sevilla, donde hoy día se conservan ${ }^{37}$.

La importancia que tiene este inventario radica en que nos permite conocer el número exacto de cuadros que tenía la iglesia y el colegio, en el momento de la expulsión, así como la apreciación que realizó Juan de Espinal, en líneas generales, indicando: no es de lo mejor; su habilidad regular; pintura regular; copia endeble; pintor sevillano y decente; pintura ordinaria; no de la mayor calidad; pintor decente; etc.

En el inventario se enumeran un total de 86 lienzos, con nombre de su autor, advocación y tamaño, en varas castellanas ${ }^{38}$ y cuartas. El listado de pinturas se presenta estructurado siguiendo la distribución de las dependencias del colegio, a diferencia de otros inventarios en los que se pone precio a los cuadros e incluso se indica como era el marco, dorado, tallado, etc., o simplemente se listan las pinturas sin indicar su ubicación ${ }^{39}$. También se hace referencia si son copias de otro pintor importante, o copias realizadas a través de láminas, por ejemplo: copia del Ticiano; copia de Rubens; copia ordinaria; copia del clérigo Roelas; copia de un pintor cordobés que llaman Castillo, etc. Respecto a la autoría de los cuadros se mencionan una serie de pintores, sevillanos que pasamos a nombrar:

- En primer lugar, destacamos la figura de Domingo Martínez (1688-1749), autor de 17 cuadros.

- Gregorio de Espinal (-1746), padre de Juan de Espinal y colaborador de Domingo Martínez como en la capilla del sagrario de la iglesia parroquial de San Lorenzo.

- Cristóbal de León, pintor sevillano (-1729).

- Cristóbal López, pintor sevillano (1671-1730).

- Juan de Roelas, pintor sevillano (1558-1625).

- Juan Simón, pintor sevillano (1634-1718).

${ }^{36}$ Archivo España de la Compañía de Jesús de Alcalá de Henares, (AESI-A). Estante 2: Caja $n^{\circ} 12$, Expediente $n^{\circ}$ 6. Inventario de pinturas del Colegio de los irlandeses de Sevilla.

37 Fernández Rojas, 2013: 38-39.

${ }^{38}$ Otorgamos un valor de $83,58 \mathrm{~cm}$ a la unidad de la vara castellana siguiendo la tabla de correspondencias de pesas y medidas de cara a la implantación del sistema métrico decimal, publicado en el número 6.763 de la Gaceta de Madrid de 28 de diciembre de 1852.

39 Martín Pradas, 2009: 317-333. 
- Miguel de Ayala, pintor sevillano. No aparece, encontramos un pintor llamado Bernabé de Ayala.

- Andrés Pérez, pintor sevillano (1660-1727).

- Matías de Arteaga, pintor sevillano (1633-1704).

Por regla general las pinturas de este colegio están realizadas por pintores sevillanos, alguno de ellos muy reconocidos como buenos artistas hoy día. En el inventario aparece mencionado Miguel de Ayala, pintor que no hemos podido localizar en las publicaciones que tratan de la pintura barroca en Sevilla. Si aparece el pintor Bernabé de Ayala, pensamos que pueda tratarse de un error ortográfico o de un artista que aún está por conocer o que tuvo una reducida producción pictórica, de ahí que no sea conocido.

\section{APÉNDICE DOCUMENTAL}

Inventario de pinturas del Colegio de los irlandeses de Sevilla.

1767, septiembre, 26.

AESI-A. Estante 2: Caja n ${ }^{\circ} 12$, Expediente $n^{\circ} 6$.

"Lista de pinturas, que se halla en el Colegio / de los Irlandeses de esta ciudad de Sevilla, su calidad / clases y autores, según el reconocimiento que / judicialmente ha hecho don Juan de Espinar, artista / pintor de esta dicha ciudad que es en la forma siguiente:

- Primeramente se pasó a la iglesia de dicho Colegio y re / conoció un lienzo de dos varas echado, pintado en él / Cristo poniéndolo en el sepulcro, copia del / Ticiano.

- Seis lienzos como de a vara y cuarta pintados de la vida de / Cristo, su autor Cristóbal López, sevillano, / la pintura no de la mayor calidad.

- Dos lienzos de vara y cuarta pintado en uno San Ignacio / de Loyola y en otro San Francisco Javier, su autor / Cristóbal de León, sevillano pintor regular.

- Cuatro lienzos de a vara y tercia pintado en el uno San / Agustín de medio cuerpo; otro Santa Teresa; otro / San Pedro; y otro San Pablo, por dicho Cristóbal de León.

- Un lienzo de cerca de siete cuartas con Cristo Crucifica / do y la Virgen, pintado por el papel de Rubens, y he / cho por Gregorio de Espinar, pintor sevillano.

- Un San Juan Regis pintado en un lienzo de a vara / de medio cuerpo, que está en un altar hecho por el / dicho Gregorio de Espinar, por una estampa.

- Siete pinturas de la vida de San Patricio que están / en su retablo como de a tercia, solo la que está, y // remata en dicho altar, es poco mayor, pintadas por Domingo Martínez, pintor sevillano.

- Diez pinturas como poco más de media vara de la vi / da de Cristo, pintada por el mismo Domingo / Martínez, en otro retablo, pintor decente. 
- Una cabecita de una imagen de la Virgen como / de a tercia, de escuela romana, no tiene la / mayor calidad.

- Y de allí se pasó a la sacristía de la iglesia en donde reco / noció un lienzo como de a vara y media, y en él pintado Cristo, copia de Rubens.

- Otro lienzo de a vara y cuarta pintado un San Luis / Gonzaga de cuerpo entero, por el dicho Gregorio / de Espinar, pintor sevillano.

- Dos pinturas como de a tres cuartas cada una, en la una / una imagen de la Virgen con el Niño, copia / de Murillo, y la otra un San José hecho / por un papel extranjero, ejecutado por el dicho / Gregorio de Espinar.

- Dos cabezas como de a cuarta, una un Ecce Homo, y la / otra una imagen de Dolores, de compañero, pintadas por Gregorio de Espinar.

- Otra cabeza de San Ignacio, del mismo tamaño, pinta / da por el nominado Cristóbal de León.

- Una imagen del Rosario, de cuerpo entero, como de una / vara, copia del Clérigo Roelas, y más arriba pin / tada una Trinidad, de la misma calidad de pintura.

- Un lienzo de dos varas y media de alto, y vara y / media de ancho, pintada la Virgen de los // Reyes con todo su retablo, ejecutado por Juan / Simón, pintor sevillano, no de la mayor calidad.

- Una chapa de cobre, como de a tercia, pintada una / imagen de la Virgen con el Niño, hecha por / un papel romano, no de la mayor calidad.

- Y de allí se pasó a la sala de conferencias baja, y se re / conoció por el dicho inteligente un lienzo de más / de tres varas y en él pintado un San Patricio / con la vida del santo alrededor, y algunos colegia / les, la pintura ordinaria.

- Y de allí se pasó a los corredores del patio de dicho colegio / en donde por el dicho inteligente se reconocieron / diez lienzos de a dos varas y media, y en cada / uno pintado un Colegial, hechos por / mano del citado Gregorio de Espinar, pintor / regular.

- Y siguiendo hacia la portería baja reconoció un lienzo / de dos varas, pintado San Francisco Javier, / es copia endeble.

- En la misma portería un lienzo de siete cuartas / pintado el martirio de Theobald Estapleton, / de nación irlandés, primer Rector, que / fue de dicho colegio, hecho por mano de Miguel / de Ayala, pintor sevillano y decente.

- En la misma portería un lienzo como de a vara // y media pintada una imagen del Pópulo, pin / tura ordinaria.

- Y de allí se pasó al refectorio en donde se reconoció / por el dicho inteligente un lienzo como de tres varas / y media pintada una Concepción por mano del Clé / rigo Roelas, pero estaba retocado por cuya razón / no tiene mérito alguno.

- En el mismo refectorio un lienzo como de a dos varas / echado, pintado un Cristo ya difunto con la / Virgen, copia muy endeble.

- De allí se pasó al aposento rectoral bajo, en donde recono / ció un lienzo como de dos varas, pintado San / Cayetano, una copia ordinaria. 
- Y de allí se pasó a la escalera principal de dicho colegio, y en la / pared de su meseta reconoció un lienzo de / tres varas, pintada una imagen del Rosario, / con su acompañamiento de ángeles y dos colegiales / al pie, copia de un pintor cordobés que llamaban / Castillo, pintura regular.

- De allí se pasó al aposento rectoral alto, en el que / reconoció un lienzo pintada una imagen de la / Virgen con el Niño y San José, como de una vara, / hecho por Andrés Pérez, pintor sevillano, endeble.

- Y de allí se pasó a la sala de conferencias alta, en don / de reconoció un lienzo de tres varas pintado / una Concepción con un acompañamiento / de ángeles, hecha por Matías de Ar / teaga, pintor sevillano, su habilidad / regular. //

- En la misma sala un lienzo de cuatro varas de un santo / diciendo misa con distinto acompañamiento / de figuras, copia del Clérigo Roelas, mal ejecutada.

- En la misma sala dos lienzos como de a vara, pintado en / uno San Ignacio y en otro San Francisco Javier / de medios cuerpos, copias y no de lo mejor.

- Y de allí se pasó al aposento del presidente en donde se reconoció / un lienzo como de media vara en cuadro, pintado / una imagen de medio cuerpo de Nuestra Señora con / el Niño, copia extranjera, no es de lo mejor.

- Y de allí se pasó a la librería en donde reconoció diecinueve / pinturas en círculo, como de cuarta, en algunas / de ellas pintadas algunas cabezas de Cristo y la / Virgen, y de la de los principales escritores de la Com / pañía, todas ellas hechas y copiadas por estampas y endebles.

- Y de allí se pasó al fin de los corredores altos, y en la pared que / está junto a la escalera de la tribuna, reconoció / un lienzo de dos varas pintado San Ignacio vesti / do de sacerdote, copia endeble.

- Y para que conste lo referido en el reconocimiento que antecede / que he practicado de orden y con asistencia del Señor Don Matías / de Ulloa, Alcalde del Crimen de la Real Audiencia de esta / ciudad. Doy la presente en ella en veinte y seis / de septiembre de mil setecientos sesenta y siete.

Fdo: Juan de Espinal”.

Fecha de recepción: 8 de agosto de 2020.

Fecha de aceptación: 2 de mayo de 2021.

\section{BIBLIOGRAFÍA}

Bravo Lozano, Cristina (2016): "El Colegio de los Irlandeses o de San Patricio de Sevilla (1612-1767). http://www2.ual.es/ideimand/colegio-de-los-irlandeseso-de-san-patricio-sevilla-1612-1767/.

Carrera, Antonio (1817): Compendio histórico de la fundación del Orden Regulares Jesuitas en Sevilla, sus progresos, expulsión, destinos que con este motivo 
se dieron a sus casas, concluyéndose con su nuevo restablecimiento en virtud de los reales decretos de nuestro católico Monarca el Señor D. Fernando Séptimo.

Colección General de las Providencias hasta aquí tomadas por el Gobierno sobre el estrañamiento y ocupación de temporalidades de los Regulares de la Compañia que existían en los Dominios de S. M. de España, Indias, e Islas Filipinas (1769). Madrid: Imprenta Real de la Gazeta.

Collantes de Terán Delorme, Francisco/Gómez Estern, Luis (1976): Arquitectura civil sevillana. Sevilla: Ayuntamiento.

Fernández Rojas, Matilde (2013): "La Compañía de Jesús en Sevilla: El Colegio Inglés de San Gregorio Magno”. En: Ucoarte. Revista de Teoría e Historia del Arte, 2, pp. 31-51.

García, Domingo (S.I.) (1727): Gemelos de la gracia, semejantes en la gloria de la canonización, S. Luis Gonzaga, y S. Estanislao Kostka: oración panegírica. https://digibug.ugr.es/handle/10481/4843?show=full.

García Hernán, Enrique: "Estudios sobre la Misión de Irlanda”. CSIC, Madrid. http://www.irishinspain.es/irlandeses/doc/research/estudiosmisionirlanda. php.

(2006): "El Colegio de San Patricio de los Irlandeses de Madrid (16211937)". En: Madrid: Revista de Arte, geografía e Historia, 8, pp. 229-246.

Gómez Rivas, León (2009): "El Colegio de los Irlandeses en Salamanca hacia 1800. Una nota sobre la correspondencia y otras circunstancias al tiempo de la invasión francesa". En: Universidades Hispánicas: Colegios y Conventos Universitarios en la edad Moderna (II). Miscelánea Alfonso IX. Salamanca: Universidad de Salamanca, pp. 273-294.

González de León, Félix (1839): Noticia histórica del origen de los nombres de las calles de esta M. N. M. L. ciudad de Sevilla. Sevilla: Imprenta a cargo de José Morales.

(1844): Noticia artística, histórica y curiosa de todos los edificios públicos, sagrados y profanos de esta Muy Noble, Muy Leal, Muy Heroica e invicta ciudad de Sevilla. Tomo I. Sevilla: Imprenta de Don José Hidalgo y Compañía.

Gutiérrez Núñez, Francisco Javier/Hernández González, Salvador (2014): “El Beaterio de San Antonio (collación de San Vicente, Sevilla). Siglos XVIIXIX”. En: Peláez del Rosal Manuel (dir. y ed.): Congreso internacional "Las clarisas, ocho siglos de vida religiosa y cultural". Actas del XVII Curso de Verano, El franciscanismo en Andalucía, (Priego de Córdoba y Jaén, 2011). Córdoba: Asociación Hispánica de estudios franciscanos, pp. 289-305.

Madoz, Pascual (1849): Diccionario geográfico-estadístico-histórico de España y sus posesiones de ultramar, Tomo XIV, Sevilla. Madrid.

Martín Pradas, Antonio (2009): "La expulsión de la Compañía de Jesús de Osuna. El Catálogo de pinturas del Colegio de San Carlos el Real". En: Archivo hispalense: Revista histórica, literaria y artística, 279-281, pp. 317-333. 
Martín Pradas, Antonio/Carrasco Gómez, Inmaculada (2005): "La expulsión de la Compañía de Jesús de Écija. El Catálogo de pinturas del Colegio de San Fulgencio". En: Actas del VII Congreso de Historia de Écija. Écija economía y sociedad. (Écija, 11-13 de diciembre de 2003). Écija: Asociación de Amigos de Écija, pp. 195-306.

Murphy, Martin (2003): "Irish students and merchants in Seville (1598-1798)". En: Villar García, M. B./Pezzi Cristóbal, P. (eds.): Los extranjeros en la España Moderna. Málaga: Gráficas Digarza, pp. 565-571.

Ortiz de Zúñiga, Diego (1796): Anales eclesiásticos y seculares de la Muy Noble y Muy Leal ciudad de Sevilla. Tomo IV. Madrid: Imprenta Real. 


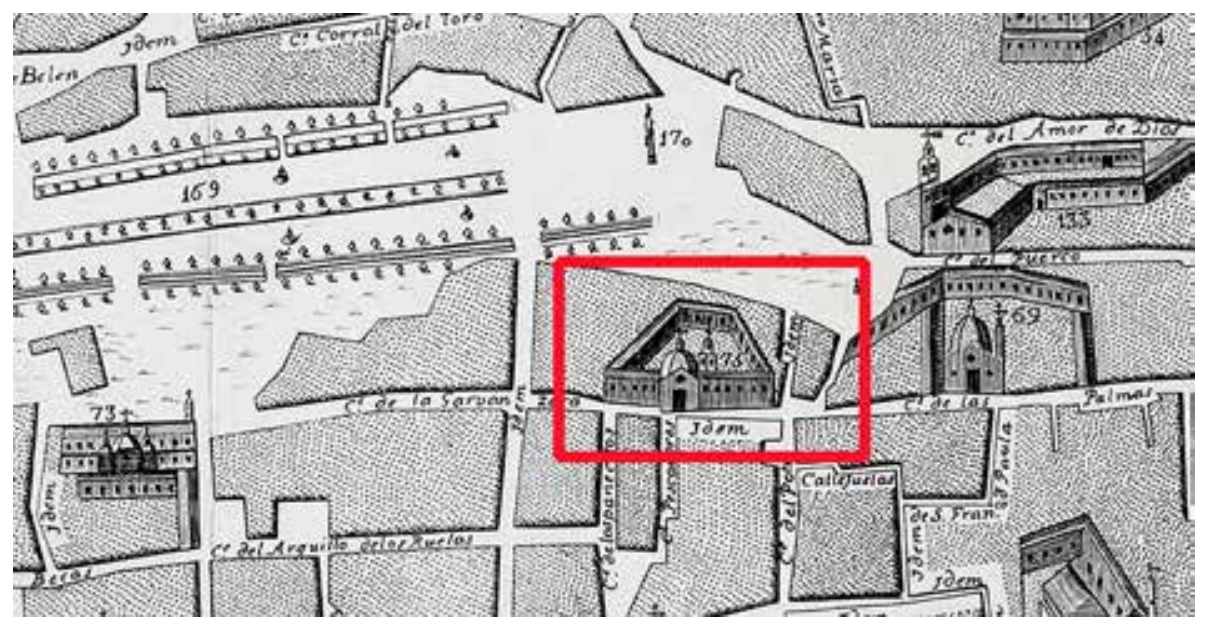

Figura 1. Plano de Olavide de 1771, donde se indica con el $\mathrm{n}^{\circ} 75$ el colegio de los Irlandeses. Se observa que la iglesia estaba situada frente a la calle Pescadores. https://bvpb.mcu.es/es/consulta/registro.do?id=423028. 


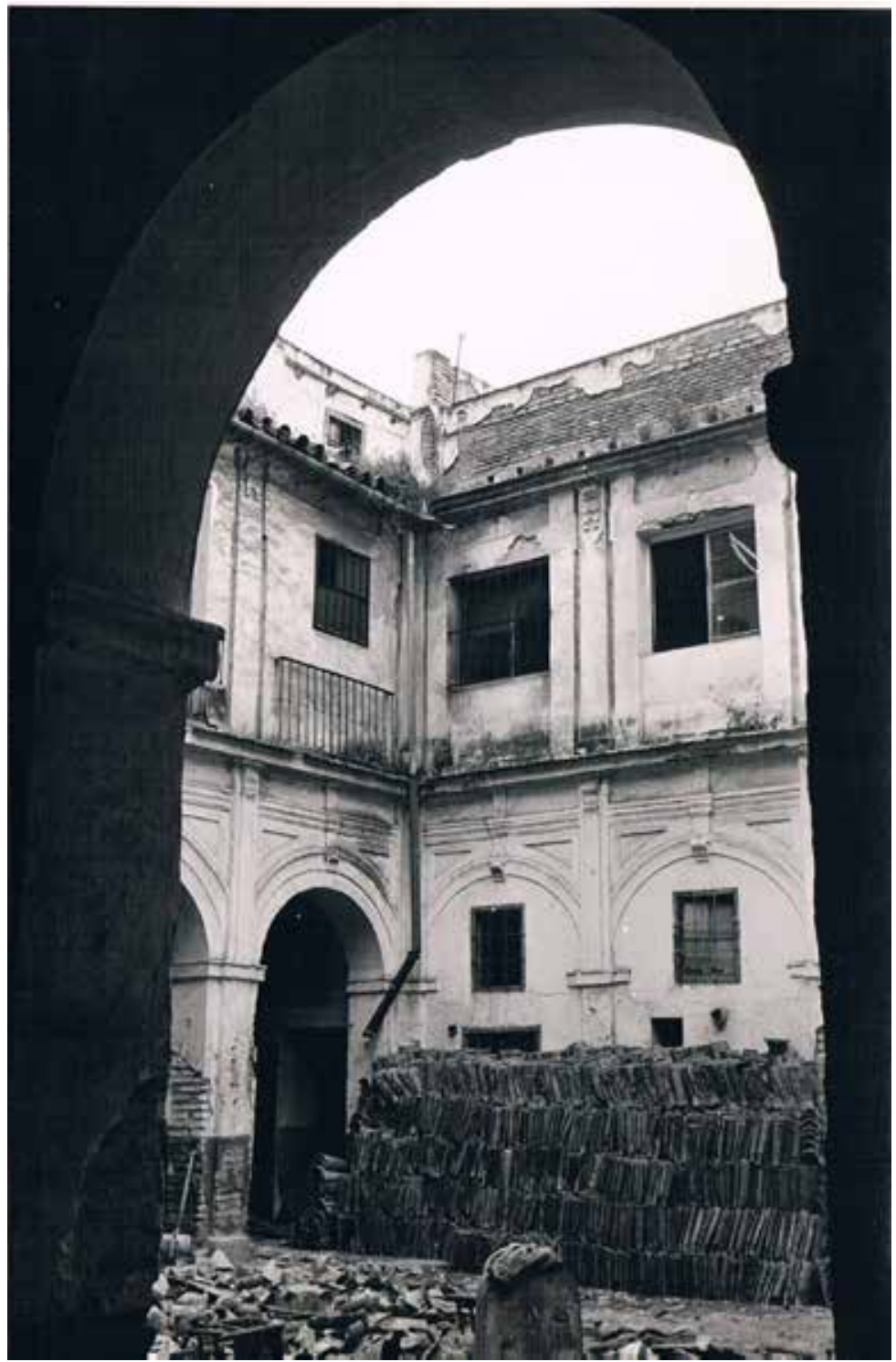

Figura 2. Anónimo. Vista del patio desde un ángulo con acopio de material. Calle Jesús del Gran Poder $n^{\circ} 66.16$ de abril de 1968. Colección Antonio Martín Pradas. 


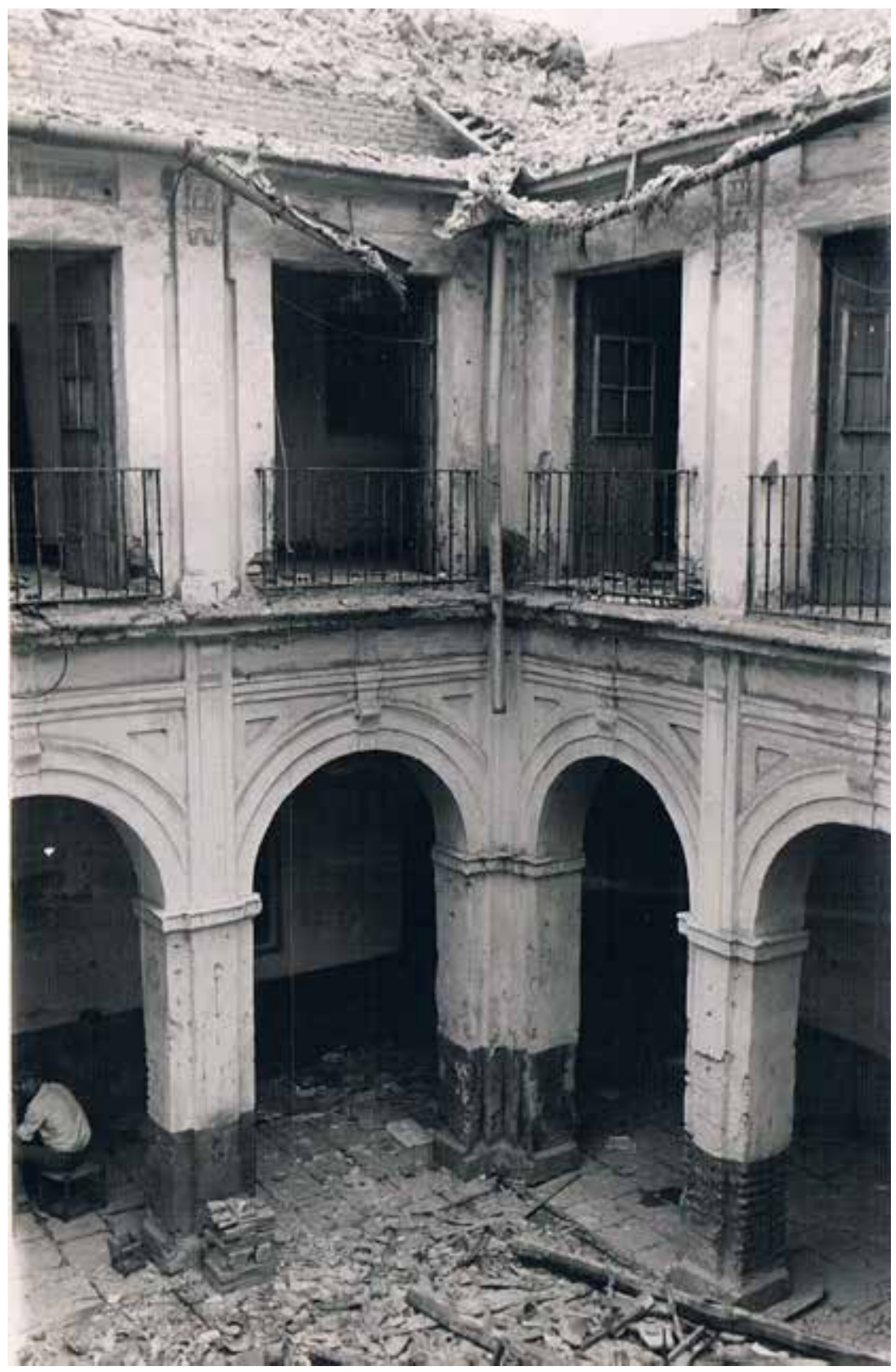

Figura 3. Anónimo. Vista de un ángulo del patio con el desmantelamiento de las cubiertas. Calle Jesús del Gran Poder no 66. 16 de abril de 1968.

Colección Antonio Martín Pradas.

LABORATORIO DE ARTE 33 (2021), pp. 275-298, ISSN 1130-5762

e-ISSN 2253-8305 - DOI http://dx.doi.org/10.12795/LA.2021.i33.14 


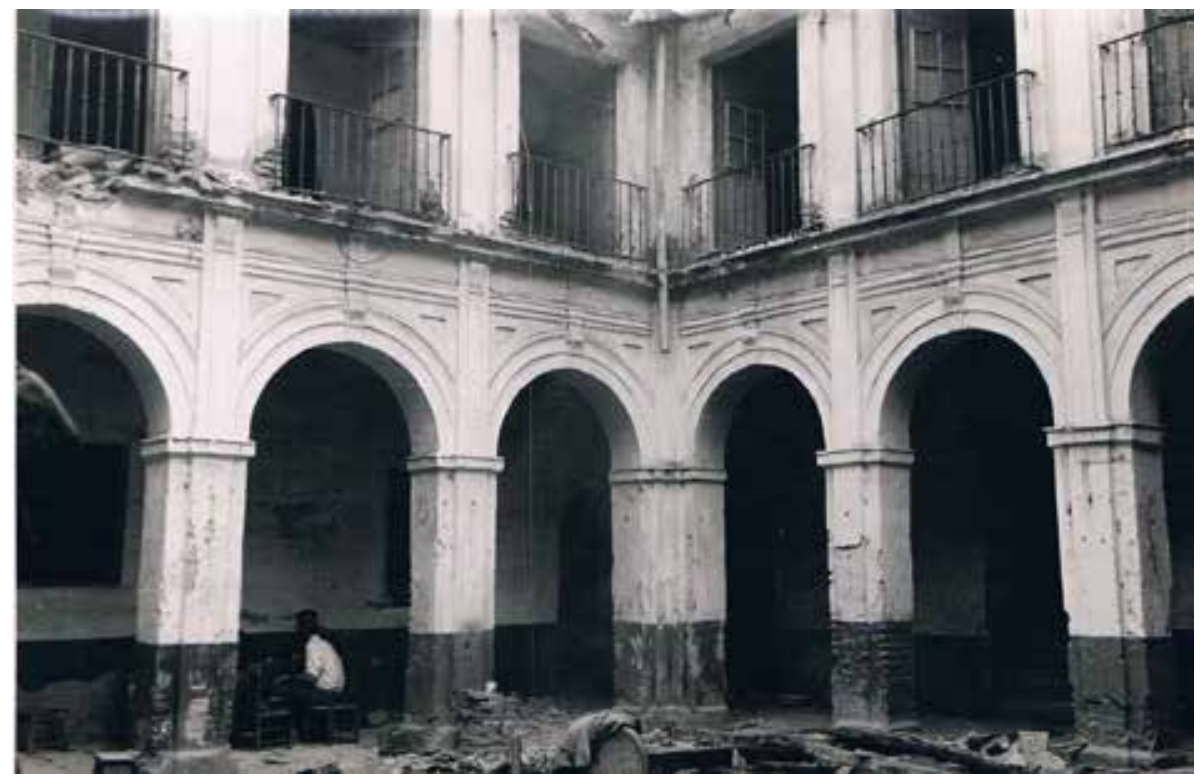

Figura 4. Anónimo. Vista de la galería inferior y superior del patio. Calle Jesús del Gran Poder $n^{\circ}$ 66. 16 de abril de 1968. Colección Antonio Martín Pradas.

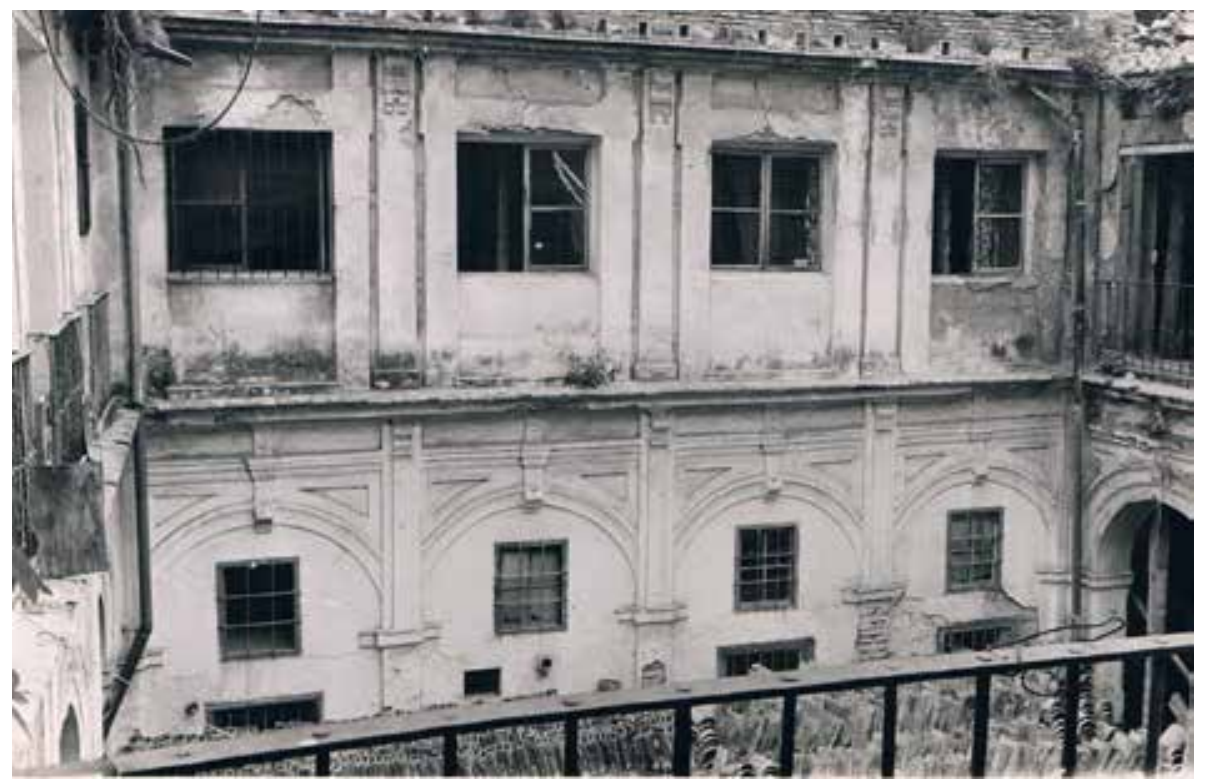

Figura 5. Anónimo. Vista del frente del patio con las galerías alta y baja cerradas. Calle Jesús del Gran Poder $n^{\circ}$ 66. 16 de abril de 1968. Colección Antonio Martín Pradas. 


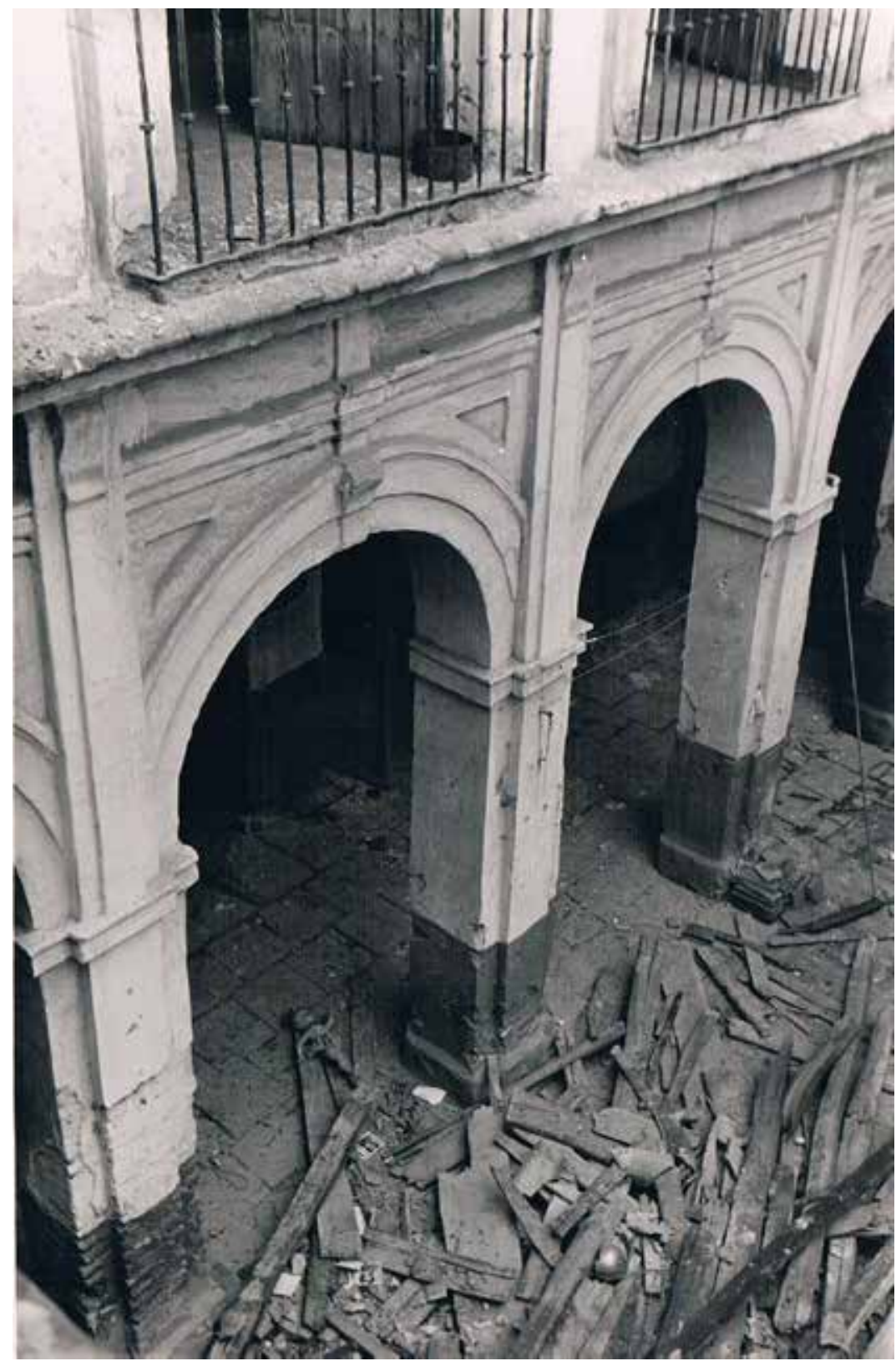

Figura 6. Anónimo. Detalle de los arcos de la galería inferior y materiales. Calle Jesús del Gran Poder $n^{\circ} 66.16$ de abril de 1968. Colección Antonio Martín Pradas. 


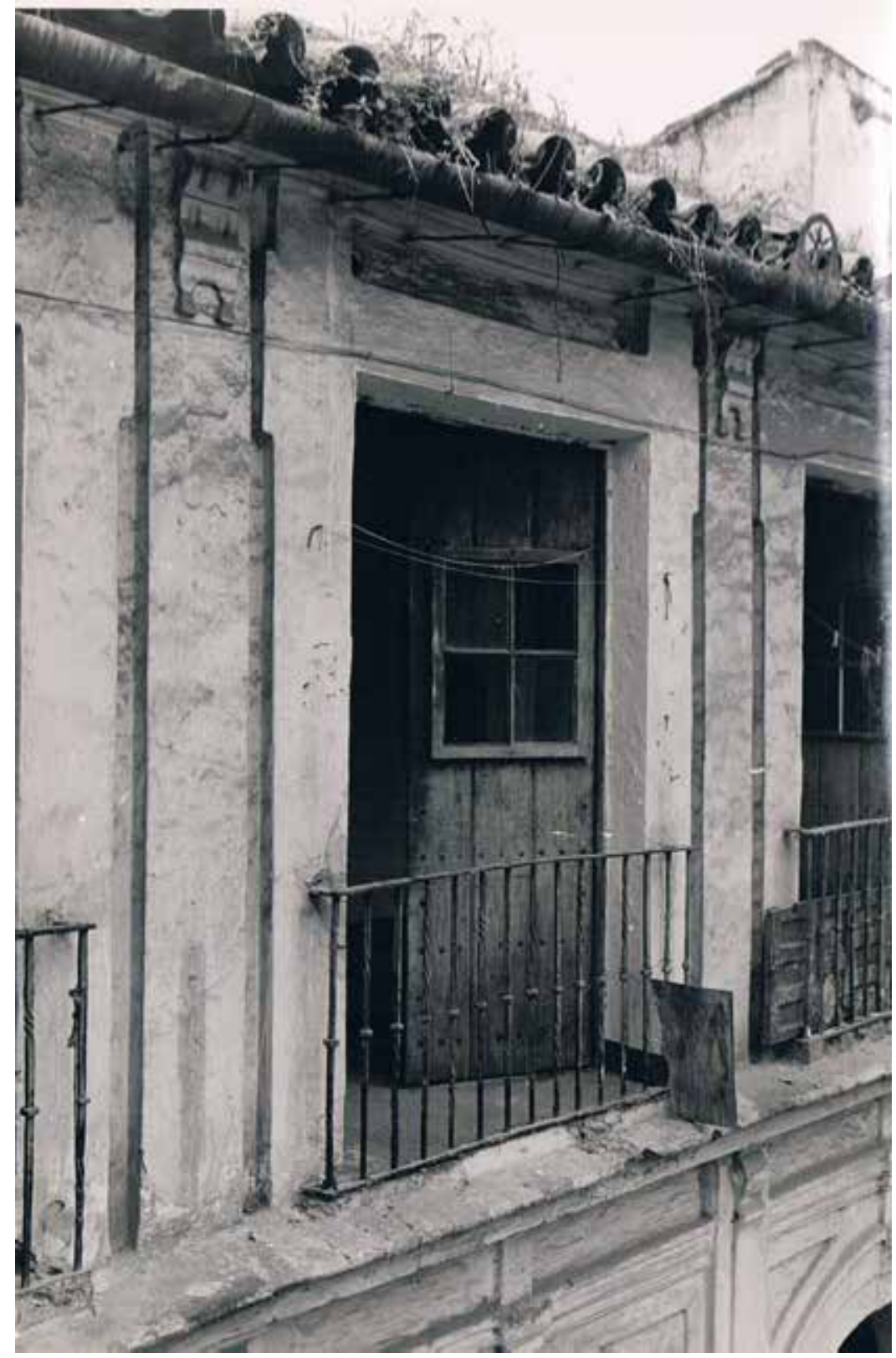

Figura 7. Anónimo. Detalle de un vano abalconado de la galería superior. Calle Jesús del Gran Poder $n^{\circ} 66.16$ de abril de 1968. Colección Antonio Martín Pradas. 


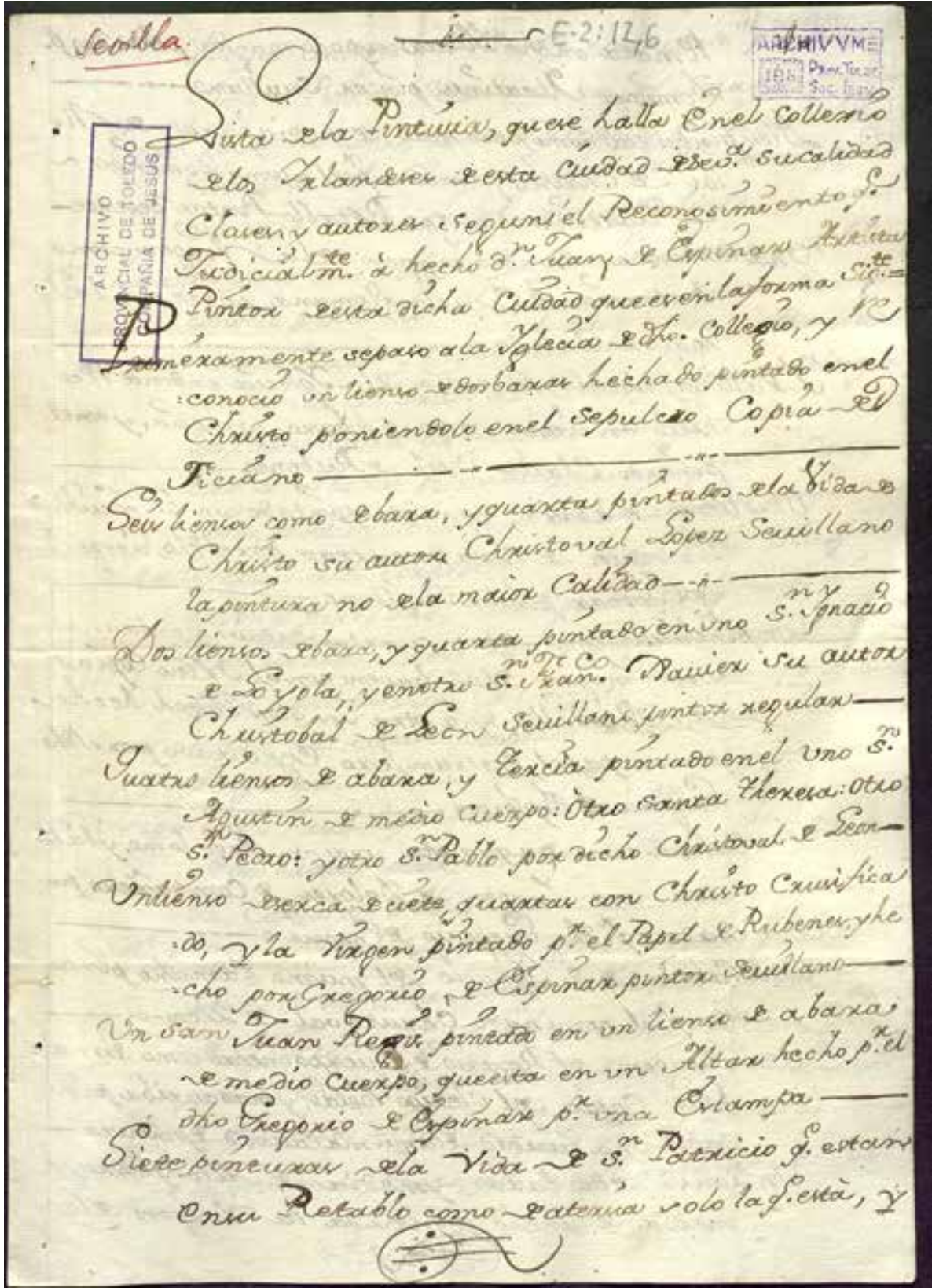

Figura 8. Inventario de Pinturas del Colegio de los Irlandeses de Sevilla (26 de septiembre de 1767). AESI-A, Estante 2: Caja ${ }^{\circ} 12$, Expediente $n^{\circ} 6$. Fotografía Antonio Martín Pradas. 